\title{
GESTANTES/PUÉRPERAS COM HIV/AIDS: CONHECENDO OS DÉFICITS E OS FATORES QUE CONTRIBUEM NO ENGAJ AMENTO PARA O AUTOCUIDADO
}

\author{
Pregnant women/ mothers with newborns with hiv/ aids: \\ understanding the deficits and factors that contribute to \\ engaging in self-care
}
Gestantes/ puérperas con el vih/ sida: conociendo los déficits y los factores que contribuyen para el compromiso con el autocuidado

\author{
Lígia Maria Scherer ${ }^{1}$
}

Miriam Süsskind Borenstein ${ }^{2}$

Maria Itayra Padilha ${ }^{3}$

\section{RESUMO}

Trata-se uma pesquisa qualitativa do tipo exploratório-descritiva cujo objetivo foi conhecer os déficits de autocuidado de gestantes/puérperas com HIV/AIDS e os fatores que influenciam no engajamento para o autocuidado. 0 estudo foi realizado com dez gestantes/puérperas com HIV que utilizam um serviço especializado em DST/AIDS no Rio Grande do Sul. Os dados foram coletados por meio de um grupo focal e entrevistas individuais, com um roteiro semiestruturado. Após análise dos dados, utilizando-se a análise de conteúdo, chegou-se aos seguintes resultados: as gestantes/puérperas com HIV apresentam déficits de autocuidado relacionados com a alimentação, ingesta hídrica, sono e repouso, vida sexual, lazer e recreação e interação social. Convivem tanto com fatores que contribuem para o engajamento no autocuidado quanto com fatores que o dificultam. Embora com dificuldades, as gestantes/puérperas têm conseguido sobreviver ao isolamento e ao preconceito graças ao apoio familiar e da equipe de saúde, em especial das enfermeiras.

Palavras-chave: Mulheres. Síndrome da Imunodeficiência Adquirida. Soropositividade para AIDS. Autocuidado. Enfermagem.

\begin{abstract}
The objective of this qualitative, descriptive, exploratory study is to better understand the deficits of self-care among pregnant women/ mothers with newborns with HIV/AIDS and the factors that influence engagement with self-care. The study was carried out with ten pregnant women/mothers of newborns with HIV who use the Specialized Service for STD/Aids in Rio Grande do Sul, Brazil. The data was collected through a focus group and individual interviews, using a semi-structured script. After analyzing the data through content analysis, the following results were reached: the pregnant women/ mothers of newborns with HIV present deficits to self-care related to nutrition and feeding, water ingestion, sleep and rest, sexual life, leisure and recreation, and social interaction. They live so continuously with factors that contribute to engaging in self-care as factors that make this process difficult. Even with these difficulties, the pregnant women/ mothers of newborns have been able to survive into the isolation, the prejudice, receiving a support from their families and from the health care team, especially from nurses.
\end{abstract}

Keywords: Women. Acquired immunodeficiency syndrome. HIVpositive. Self-care. Nursing.

\section{Resumen}

Se trata de una investigación de carácter cualitativo, exploratoria descriptiva, cuyo objetivo fue conocer las faltas con el autocuidado de las gestantes/puérperas con VIH/SIDA, así como los factores que contribuyen para su compromiso con ese autocuidado. El estudio fue realizado con diez gestantes/ puérperas con VIH/SIDA que utilizaron un servicio especializado en DST/SIDA, en el Estado de Rio Grande do Sul - Brasil. Los datos fueron colectados a través de sesiones de grupo, y también por medio de entrevistas individuales con un esquema parcialmente elaborado. Después de realizar el análisis de los datos, utilizando para ello el análisis del contenido, se obtuvieron los siguientes resultados: las gestantes/puérperas con VIH presentan dificultades en el autocuidado que están relacionadas con la alimentación, la ingestión de líquidos, sueño y descanso, vida sexual, ocio, recreación, e integración social. Las gestantes/ puérperas conviven con factores que contribuyen para el compromiso con el autocuidado, así como con factores que lo dificultan. Pero a pesar de las dificultades, ellas han conseguido sobrevivir al aislamiento y al prejuicio gracias al apoyo familiar y a la ayuda del equipo de salud, especialmente de las enfermeras.

Palabras clave: Mujeres. Síndrome de inmunodeficiência adquirida. Soropositividade para VIH. Autocuidado. Enfermería

'Mestre em Enfermagem - UFSC, Professora de Pós-Graduação em Materno-Infantil do Instituto de Educação e Pesquisa - IEP do Hospital Moinhos de Vento. Brasil. E-mail: ligiascherer@yahoo.com.br, ²Doutora em Filosofia de Enfermagem - UFSC, Professora Associada do Departamento de Enfermagem - UFSC, Vice-Coordenadora do GEHCE, Pesquisadora do CNPq. Brasil. E-mail: miriam@nfr.ufsc.br, ${ }^{3}$ Doutora em Enfermagem - Escola Anna Nery - UFRJ, Professora Associada do Departamento de Enfermagem - UFSC, Coordenadora do GEHCE, Pesquisadora do CNPq. Brasil. E-mail: padilha@nfr.ufsc.br 


\section{INTRODUCÃO}

Descoberto em meados dos anos 80, o HIV/AIDS, inicialmente sem tratamento ou cura, esteve associado a chamados "grupos de risco", tais como homossexuais e posteriormente prostitutas, dependentes químicos e hemofilicos. Desta forma, a população, de um modo geral, acreditava que se não fizesse parte desses grupos, estaria a salvo do problema de saúde, além de reforçar o preconceito contra essas pessoas ${ }^{1}$.

Possivelmente em decorrência desse pensamento, a epidemia se alastrou e atingiu outros grupos populacionais, como o das mulheres, o que é chamado de feminilização da epidemia. Isso pode ser verificado pelos dados estatísticos do Ministério da Saúde, que, no ano de 1993, em relação à faixa etária compreendida entre 20 e 34 anos de idade, apresentou 20.813 casos notificados de homens e apenas 4.990 casos notificados de mulheres. No ano de 2004 , foram notificados 3.117 casos de homens na faixa dos 20 aos 34 anos de idade e 2.457 casos de mulheres nesta mesma faixa etária. Com estes dados, é possível perceber que o número de casos entre homens e mulheres, que era de 4 para 1, no ano de 2004, passou a ser praticamente de 2 para 1,272. As ações do Ministério da Saúde para o combate à AIDS entre as mulheres buscam chamar a atenção destas para a existência de uma epidemia entre elas e para a percepção de que são vulneráveis e que devem procurar mecanismos para sua proteção. Referem, ainda, que as mulheres devem ser protagonistas da prevenção e da conquista de acesso à saúde e aos direitos fundamentais para o exercício da cidadania. A realização do exame para sorologia do HIV no pré-natal não é uma medida preventiva; porém, é um momento em que as mulheres têm acesso a um aconselhamento no qual estão inclusas medidas preventivas de DST/AIDS e comportamento de risco, além de ser uma oportunidade de descobrir a sorologia e iniciar o tratamento.

Esta conquista científica (antirretrovirais) e de ação do governo brasileiro melhorou de forma expressiva a qualidade de vida dos portadores de HIV/AIDS e a imagem da doença, mas não impediu que ela continuasse se alastrando e recebendo novas orientações. A AIDS expandiu-se na periferia das cidades, no interior (onde a população é mais pobre e com baixa escolaridade, o que é chamado de pauperização e interiorização) e entre as mulheres ${ }^{3}$.

As questões discriminatórias em relação ao portador do HIV/AIDS ainda existem.e são marcantes, o que se observa com frequência na prática dos serviços de saúde. Em nossa vivência como enfermeiras e professoras, verificamos que algumas gestantes portadoras de HIV, atendidas em um hospital de médio porte, no interior do estado do Rio Grande do Sul, chegavam em período expulsivo, sem possibilitar a administração do antirretroviral endovenoso indicado pelo Ministério da Saúde, nas três horas que antecediam ao parto ${ }^{4}$. Outras chegavam sem o resultado da sorologia para o HIV, mesmo tendo sido feita a coleta ambulatorial. Quando aconselhadas para a realização do teste rápido para HIV, mencionavam que já haviam recebido este aconselhamento e sabiam da sua importância, não se indispondo à sua realização; no entanto, não haviam buscado o resultado no ambulatório. Estas situações demonstravam claramente o desconhecimento em relação ao seu autocuidado e a falta de percepção a respeito do seu papel, como agente ativo no processo de saúde/doença.

Este artigo é resultado de uma pesquisa qualitativa a , que teve como objetivo conhecer os déficits de autocuidado de gestantes/puérperas com HIV/AIDS e os fatores que influenciam no engajamento ou não do autocuidado.

\section{METODOLOGIA}

Trata-se de um pesquisa qualitativa do tipo exploratóriodescritiva, realizada com dez gestantes/puérperas com HIV que frequentaram um serviço especializado em DST/AIDS em um município do interior do Rio Grande do Sul. Elas foram selecionadas a partir de alguns critérios, tais como: ser gestante ou puérpera; estar acometida pelo HIV; ter disponibilidade de participar dos encontros; e aceitar participar do estudo.

Antes da coleta de dados, as gestantes/puérperas foram orientadas quanto aos objetivos do estudo, à assinatura do Termo de Consentimento Livre e Esclarecido e ao sigilo sobre as informações prestadas (seus nomes foram substituídos pelos de flores), de acordo com a Resolução 196/96 do Conselho Nacional de Saúde ${ }^{5}$. A pesquisa foi aprovada em 06/03/2006 pelo Comitê de Ética e Pesquisa da Universidade Federal de Santa Catarina, recebendo o número de protocolo 045/06. A coleta de dados ocorreu entre março e maio de 2006. Para tanto, foram desenvolvidos encontros individuais em que foi aplicado um instrumento previamente elaborado, baseado na Teoria do Autocuidado de Dorothea Orem. Foi ainda realizado um grupo focal, que teve por finalidade obter respostas mais consistentes para questões que ficaram pendentes. Todos os encontros foram gravados e transcritos na íntegra e, depois, categorizados. Quanto à análise, utilizou-se a análise de conteúdo ${ }^{6}$. Foram encontradas as seguintes categorias de análise: 1) Os déficits de autocuidado; 2) Fatores que contribuem no engajamento do autocuidado.

\section{APRESENTAÇÃO E DISCUSSÃO DOS RESULTADOS}

\section{Os Déficits de Autocuidado}

A Teoria do Déficit de Autocuidado constitui a essência da Teoria Geral da Enfermagem de Dorothea Orem. Nela se observa a necessidade da presença da enfermagem, ou seja, quando e por que o indivíduo, família ou o grupo social necessita ser ajudado pelos profissionais e pelas ações desenvolvidas. Estas ações passam a ser executadas quando um adulto ou familiar se encontra incapacitado ou limitado, para prover autocuidado contínuo e eficaz ${ }^{7}$. Neste estudo, foram 
identificados déficits de autocuidado relacionados a alimentação, ingesta hídrica, sono e repouso, vida sexual, solidão e interação social.

\section{Alimentação}

As gestantes/puérperas revelaram alguns déficits de autocuidado quanto à alimentação, especialmente em relação à frequência e ao número de refeições:

Eu faço em média três refeições por dia::café da manhã, almoço, janta, lá na firma. É que na firma não tem horário, às vezes é a cinco e meia da tarde, às vezes, é às seis. Não direto, não posso fazer lanche. (Orquídea).

Logo que eu descobria doença, eu tive uma profunda depressão. Fiquei uma semana sem me alimentar, só tomando chimarrão. (Jasmim.)

Sabe o que é? Quando eu ganhei o nenê eu era um palitinho. Eu achei que ia morrer! Eu me levantava de madrugada pra comer (Amor Perfeito).

Esses depoimentos revelam que as recomendações apregoadas pelo Ministério da Saúde para uma alimentação saudável não têm sido seguidas à risca. Ao contrário de poucas refeições, o Ministério sugere que estas sejam mais frequentes, em média seis vezes por dia $^{8}$. Em decorrência de terem contraído o HIV, as participantes revelaram que aumentaram o número das refeições, por medo de morrer, de ficarem magérrimas ou com aspecto de doentes terminais. Esta ideia provavelmente estava relacionada à imagem da doença, no início da epidemia, quando ainda não existia uma boa expectativa de vida e as medicações não estavam ao alcance de todos.

Os especialistas que atuam com pessoas com HIV/AIDS referem que, quando uma gestante soropositiva não se alimenta bem, poderá agravar ainda mais o seu estado, tornando-se mais susceptível às infecções e complicações, não respondendo ao tratamento. Em decorrência disso, uma gestante desnutrida, infectada pelo HIV, poderá desenvolver os sintomas da AIDS mais rapidamente que as bem nutridas ${ }^{9}$.

É sabido que uma alimentação balanceada é indispensável para qualquer ser humano. Não basta comer todos os tipos de alimentos/nutrientes, é necessário saber dosá-los para a manutenção de uma vida saudável, que implica manter também um índice de massa corporal adequada. 0 que as gestantes/ puérperas revelaram é importante para os profissionais da saúde. Estes, de posse de algumas informações, adquirem melhores condições para orientar a clientela. A Teoria de Sistemas de Enfermagem (que constitui a Teoria Geral de Enfermagem de Orem) propõe o sistema de apoio à educação. Esse apoio deve ser desenvolvido pela enfermeira, com vistas a promover o paciente a um agente de autocuidado. Está mais relacionado com as tomadas de decisão, a mudança de comportamento e a aquisição de novos conhecimentos e habilidades ${ }^{7}$.

Ao trabalhar a questão alimentar, é preciso levar em conta que, para muitas pessoas, comer é a coisa mais importante do mundo, talvez um dos maiores prazeres da vida; para outras, uma grande compensação. 0 simples fato de alguém chegar e impor o abandono de determinados hábitos alimentares de uma vida inteira é difícil e pode parecer quase impossível. Por esse motivo, é impor tante conhecer quem é este ser humano que necessita se adequar e até mudar seus hábitos alimentares, para somente, então, desenvolver alternativas razoáveis de adequação, que permitam transformaç̧ões sem "privar" a pessoa dos prazeres ou sacrificá-la ${ }^{10}$.

\section{Ingesta Hídrica}

Durante a gestação ocorrem modificações funcionais e anatômicas no sistema urinário, podendo persistir até seis semanas após o parto. Os rins crescem cerca de $1,5 \mathrm{~cm}$ pela maior vascularização e pelo aumento do espaço intersticial. 0 volume renal aumenta $30 \%$ à ultrassonografia por aumento do fluxo plasmático e da filtração glomerular. Ocorrem, ainda, aumento do néfron e dilatação dos cálices, da pelve renal e ureteres, em decorrência da hipotonia muscular causada pela progesterona, logo no início da gestação $\left(10^{a} \text { semana }\right)^{11}$ Esta dilatação é mantida, posteriormente, pela compressão mecânica do útero gravídico, mais acentuada à direita pela sua dextrorrotação. Além de dilatados, os ureteres tornam-se tortuosos. Com o evoluir da gestação, a bexiga eleva-se estirando a área do trígono e modificando a porção intravesical do ureter, favorecendo o refluxo urinário e consequentes infecções. Todas estas modificações contribuem para a estase urinária e 0 crescimento de bactérias. A infecção urinária é a infecção mais comum e a primeira causa de sepse durante a gestação, além de se associar a trabalho de parto prematuro e suas complicações. Neste estudo, observamos que as gestantes/ puérperas apresentam déficit de ingesta hídrica, ingerem menos líquidos do que o recomendado, como pode ser constatado em suas falas:

Não bebo muita água, numa base de um litro por dia. (Violeta)

De manhã, em casa, tomo só um copo de suco, ou de água, ás vezes mais um pouco mais. (Orquídea)

Meu sono agora tá ruim, pois eu tenho que levantar muito de noite para ir ao banheiro, tô com problema de bexiga, mas hoje vou à médica consultar e fazer os exames de urina....bom, eu tenho sempre esse problema de infecção faz uns oito anos. (Orquídea) 
Todos os organismos vivos apresentam em torno de $50 \%$ a $90 \%$ de água. 0 corpo humano é $70 \%$ constituído de água, que, em constante movimento, hidrata, lubrifica, aquece, transporta nutrientes, elimina toxinas e repõe energia, entre outras inúmeras utilidades. Em constante renovação, um indivíduo adulto perde, por dia, em condições normais, uma média de 2,5 litros de água (cerca de $800 \mathrm{ml}$ pela expiração e urina, 1,2 litros pela transpiração e 0,6 litros pelas evacuações fecais). Sendo assim, um adulto normal deveria ingerir, por dia, uma média de dois litros e meio de líquidos, a fim de evitar a desidratação $0^{12}$.

0 organismo elimina a água de várias maneiras, pela urina, transpiração, fezes, e outros. Por esse motivo, é necessária uma adequada ingestão de líquidos para que o organismo mantenha o equilíbrio hidroeletrolítico. Quando diagnosticamos nas gestantes/puérperas déficit de ingestão hídrica, devemos enfatizar que elas devem aumentar a ingestão de líquidos, por meio de bebidas que agradam e fazem bem, em especial aquelas mais naturais possíveis (água, chás, sucos, chimarrão, entre outros).

\section{Sono e repouso}

O sono é um estado de repouso normal e periódico, que se caracteriza especialmente pela suspensão da consciência, pelo relaxamento dos sentidos e dos músculos, pela diminuição do ritmo circulatório e respiratório e pela atividade onírica (sonhos). 0 sono é uma necessidade física primordial para uma boa saúde e uma vida saudável, na qual há uma restauração física que protege o ser do desgaste natural das horas acordadas ${ }^{13}$.

As gestantes/puérperas do estudo, ao rememorarem a descoberta do HIV, revelaram que esta provocou alterações profundas no seu sono e repouso, em decorrência da ansiedade gerada pela doença. Passaram a apresentar constantes alterações como insônias, conforme pode ser visualizado nas falas a seguir:

Às vezes eu acordo às duas horas, e vou dormir de novo ali por umas quatro horas da madrugada; às vezes o nenê chora, aí então eu demoro de novo para dormir. Às vezes fico pensando nisso e não consigo dormir. (Hortência)

\section{Eu durmo bem por causa dos remédios que eu estou tomando. Eu não dormia nem de noite nem de dia. Isso entrou na minha vida, no começo eu achei que isso era uma doença terminal, que eu ia morrer, que eu ia durar uns meses.. .Mas, se eu tomar os remédios direitinho, eu acho que um dia vou ficar sem o vírus, vou acordar e estar boa! Pra mim eu penso isso! (Tulipa)}

Dar apoio, ouvir suas queixas, pode ser, neste momento, um fator facilitador do(a) enfermeiro(a) diante da angústia apresentada pela portadora de HIV. Essas ações podem propiciar um nível de relaxamento que permita a gestante/ puérpera conseguir dormir, relaxar e contribuir com sua saúde tanto física como mental. Outra questão que pode ser enfatizada às gestantes/puérperas é o estímulo às atividades físicas que promovem naturalmente a liberação de endomorfinas, enzimas que provocam um relaxamento e um intenso bem-estar, podendo auxiliar na indução do sono. Outros autores recomendam, ainda, atividades como leitura, banho morno e a ingestão de leite antes de deitar ${ }^{10}$.

\section{Vida sexual}

Hoje, o principal método de prevenção do contágio do HIV é o método de barreira, ou seja, a utilização de preservativos. 0 estabelecimento de vínculos conjugais tem o poder de gerar sentimentos de proteção e confiança entre parceiros, que, em geral, não se sentem suscetíveis ao contágio

Nós não estamos usando camisinha porque ele não quer usar, eu já tentei usar até aquela camisinha das mulheres, mas ele não quer. (Hortência)

Para mim também é difíiil! Com o meu outro, foi mais fácil, mas esse agora tá difícil, não quer de jeito nenhum! Eu digo pra ele: por favor vamos nos cuidar, mas não quer usar! (Amor Perfeito)

Além do fato de não quererem utilizar o preservativo como forma de proteção, alguns parceiros soronegativos têm esta postura como prova de amor, ou seja, o amor existente entre ambos parece ser mais forte do que a possibilidade de adquirir um vírus. Há aqueles que não querem utilizar o preservativo para se tornarem mais iguais, demonstrando serem mais próximos, unidos, mais companheiros.

Quando meu marido descobriu que eu tinha HIV, eu morria de medo, achei que ia ficar sozinha e grávida ainda, mas quando as gurias contaram pra ele, ele ficou muito mais amoroso que antes, ele nem queria usar camisinha, pois ele disse se tu tem, eu também quero ter. (Girassol)

As estatísticas têm comprovado que a doença se intensificou, em especial no que se refere à feminilização. Isso se deve, particularmente, à maior exposição da mulher, em decorrência de sua vulnerabilidade biológica, e também ao baixo poder de decisão destas nas questões que envolvem a vida sexual e reprodutiva. Tanto as mulheres quanto seus parceiros/homens acreditam na invulnerabilidade feminina ${ }^{3}$.

Na busca pela promoção do autocuidado com portadoras do HIV, cabe à enfermeira, enquanto educadora, proporcionar o maior número de informações possível quanto ao uso do preservativo e sua implicação direta com o HIV. É importante ressaltar que, se por um lado, evita o contágio do parceiro 
soronegativo, por outro, evita o aumento da carga viral na cliente já infectada quando o parceiro for soropositivo, pois, a cada ejaculação, o homem introduz na mulher uma carga viral a mais, interferindo no seu quadro clínico.

As condutas referentes ao autocuidado são diretamente influenciadas pelo autoconceito e pelo nível de maturidade que a pessoa tem. Portanto, a maneira como a mulher se coloca frente ao parceiro e o seu grau de maturidade podem implicar as decisões de usar ou não o preservativo. Esses fatores são decisivos na condução do autocuidado e de preservação de saúde. ${ }^{7}$

\section{Solidão e interação social}

Assim como diminuíram as atividades de lazer, as gestantes/ puérperas com HIV também passaram a restringir sua interação social. Assumiram a atitude de querer ficar só, ficar mais em casa, o que trouxe como consequência uma redução em sua rede social. Em um estudo realizado com mulheres com HIV, as autoras encontraram o medo, a insegurança, a busca do isolamento e a solidão como respostas à nova realidade ${ }^{14}$. Neste estudo, a falta de interação social pode ser visualizada nos seguintes relatos:

Mudou só o meu pensamento...meu paie minha mãe, meus irmãos sabem, mas meus filhos não, eu tenho medo. (Girassol)

No meu bairro, eu conheço muito quem tem a doença, tem vários!! Alguns falam pra todo mundo. Eu já não falo. Eu tenho medo que vão me rejeitar, principalmente meus filhos. (Girassol)

Eu não contei para ninguém quase, ficou só entre meu marido e eu, e as enfermeiras e meu médico na minha familia; ninguém sabe. Eu penso que, se foi difícil pra eu aceitar, eles vão ficar com isso na cabeça; por causa disso eu já nem procuro falar. (Violeta)

Quando a interação social é muito restrita, ou seja, a rede de suporte social não propicia muitas possibilidades para a portadora de HIV, a enfermeira pode contribuir muito com um contato mais permanente, por meio de consultas ambulatoriais, visitas domiciliares e até mesmo de grupos de autoajuda. Segundo a Teoria do Autocuidado, é neste momento que a enfermeira pode lançar mão de métodos de ajuda, proporcionando ambiente e estratégias que promovam 0 desenvolvimento pessoal, tornando a pessoa capaz de satisfazer suas demandas atuais e futuras ${ }^{7}$.

\section{FATORES QUE CONTRIBUEM NO ENGAJ AMENTO DO AUTOCUIDADO}

\section{Rede de apoio familiar e social}

A família caracteriza-se como o núcleo base da sociedade. Nela nascemos, crescemos e adquirimos muitos dos valores que servirão de base para nossa vida presente e futura. Em um estudo, os autores referiram a importância da rede de apoio familiar para as gestantes. A participação do pai na vida familiar, a participação em especial das avós maternas nos cuidados com a gestante/puérpera e o bebê, bem como 0 apoio psicológico recebido foram considerados de maior relevância ${ }^{15}$.

Nesse estudo, as gestantes/puérperas revelaram a importância da rede de apoio familiar para esta nova fase da vida da mulher, o vir a ser mãe. Isso nos faz refletir sobre as dificuldades enfrentadas pela portadora do vírus do HIV, que, em muitas situações, não pode contar com a ajuda de sua família. Tem de tomar atitudes, como dar medicação ao recémnascido, cuidando para que ninguém descubra, e, ainda, não pode socializar suas angústias, sobre, por exemplo, o fato de não amamentar, sua permanência no hospital, o uso das medicações, entre outros assuntos que afetam a vida desta gestante. Desta forma, quando a família sabe e apoia a gestante/puérpera com HIV, essa vivência passa a ser menos sofrida:

Apoio eu tenho, tenho minha mãe, vó, dinda, que sabem, e meu namorado, que dão o maior apoio. Sabe, tem pessoas que abandonam, né? Mas elas não, desde o começo ficaram do meu lado. (Margarida)

[...] minha mãe, meus irmãos, toda a minha família me dão o maior apoio, e me ajudam, isso eu não posso negar! Eles sempre me ajudaram, nunca me botaram pra baixo! Jamais eles me discriminaram! (Amor Perfeito)

Dois autores em estudo realizado com a família como suporte à gestante encontraram o marido, ou o pai da criança, como a pessoa mais citada pelas gestantes ${ }^{16}$. Como aquele que ouve queixas, compartilha sentimentos, dá atenção, esclarece dúvidas, além de ser o provedor financeiro. Também destacam a importância da mãe, das irmãs, dos irmãos, tias e outros parentes consanguíneos enquanto rede de apoio. Destacaram que a mãe e as irmãs servem para dar conselhos e esclarecer dúvidas, provavelmente em função de experiências vividas. As gestantes também encontram suporte fora do âmbito familiar com as amigas, vizinhas, patroa, colegas de trabalho e outras gestantes.

Estes dados reforçam os resultados encontrados em nossa pesquisa, pois a maioria das gestantes/puérperas com HIV referiram o marido como a principal pessoa da família com quem dividem sentimentos e angústias, quando não é a única: 
Meu marido é a única pessoa da minha família que sabe o que eu tenho, minha mãe é doente, então não dá pra contar pra ela! (Hortência)

Ficou só entre eu e meu marido, às vezes nós conversamos sobre o assunto, mas eu tomo meus remédios, e as vezes eu tô me esquecendo e então ele diz pra mim se não tá na hora e se eu já tomei! (Violeta)

Porque, antes de acontecer isso, nós nunca nos demos, e agora, depois que isso ocorreu, que a gente ficou sabendo, eu chego lá e ele já me chama pro canto, aí a mãe diz já vão começar os dois de conversinha, aí ele me pergunta como é que eu tô, sabe?Como é que tá o vírus, se tá alto ou se tá baixo, se eu tô me cuidando, se eu tô tomando a medicação. Ele tem um cuidado assim de pai mesmo sabe, e isso eu fiquei muito feliz. Eu acho que ele não agiria tanto assim comigo, de me cuidar. (Tulipa)

Autoras que estudaram a convivência familiar do portador de HIV e do doente de AIDS encontraram os sentimentos de solidão e isolamento do portador de HIV/AIDS, demonstrando a relevância do suporte familiar no processo de adaptação à nova condição de vida ${ }^{15}$. Sentimentos como solidão, perda do significado da vida e desesperança, sentimentos de ambivalência entre contar e não contar e para quem contar sobre a doença, apareceram. A pessoa com HIV/AIDS, após passar pela fase de querer manter sigilo, procura os amigos, grupos, e alguns só em fase muito avançada procuram a família.

Em nossa experiência, foram encontradas situações semelhantes. A maioria das gestantes/puérperas com HIV contou seu diagnóstico apenas para o marido, algumas também contaram para a mãe. Alguns maridos informaram à família sobre a sorologia da esposa, para aliviar sua própria responsabilidade.

Nesse sentido, talvez fosse adequado estimular às gestantes/puérperas com HIV a ampliar sua rede de apoio familiar. A partir daí, seria possível que elas obtivessem maiores benefícios, como o apoio e compreensão, melhorando sua autoimagem e autoestima, contribuindo para o seu autocuidado.

\section{Rede de apoio profissional}

A política do Ministério da Saúde na luta contra a AIDS tem tido muito sucesso, e seus esforços são indiscutíveis. Aspectos como a distribuição universal e gratuita de medicamentos antirretrovirais pelo SUS, implementada desde 1997, teve repercussão mundial. Porém, em alguns locais do país, têm sido observados desatenção, descaso e maus tratos aos usuários no SUS. A Associação Brasileira Interdisciplinar (ABIA) de AIDS publicou algumas reclamações de usuários do sistema.
Atualmente, quando alguém decide saber se é infectado ou não pelo vírus do HIV, tem de estar disposto a enfrentar algumas situações adversas, como demora no resultado, após percorrer postos de saúde para ver onde há disponibilidade de atendimento. Esta é a realidade encontrada nos grandes centros do país 5 .

Como este estudo foi desenvolvido em um município de médio porte do interior do estado do Rio Grande do Sul, a realidade percebida foi muito diferente. Assim como a rede de suporte familiar é muito importante para o portador do vírus HIV, a rede de suporte profissional também é indispensável, e, neste caso, os profissionais da saúde proporcionaram às gestantes/puérperas, além de atendimento à saúde, apoio psicológico e social, como pode ser observado a seguir:

\section{Eu só converso sobre o meu problema aquino SAE com as gurias! (Hortência)}

A Doutora S. e as gurias, elas que me ajudaram a enfrentar isso. Quando eu tava morrendo no hospital, ela vinha do meu lado, me dizia te anima, eu vou te botar de pé outra vez; me fazia eu sentar na cama, eu ficava um pouco, ela me segurava; eu tinha vontade de vomitar, ela me alcançava aquela travessinha e ficava do meu lado! Tu vai falar, tu vai andar, vai criar teus filhos e teus netos! Quando eu via tava mais de meia hora sentada! (Girassol)

No começo eu tava com um pouco de medo, chorei um pouco, mas foi maravilhoso, pois foi a primeira vez que eu pude falar e saber de uma outra mulher como foi a sua experiência. Porque, tu sabe, tu foi a única pessoa com quem eu falei assim, mais tempo, eu confiei muito em ti, e agora é isso, meu nenê é negativo! (Rosa)

Podemos perceber, ao longo deste período de convivência com a equipe do serviço de atendimento de gestantes/ puérperas, o grau de comprometimento profissional e social das profissionais para com as clientes. Este compromisso foi manifestado pela busca destas clientes quando as mesmas não compareciam ao serviço, pelo apoio psicológico, escutando, dando conselhos, recebendo, em contraponto, o retorno afetivo e agradecimentos.

Todas as gestantes/puérperas com HIV deste estudo referiram-se aos profissionais e ao serviço com carinho e respeito, enfatizando a habilidade destes em revelar 0 diagnóstico durante 0 aconselhamento.

A realização do encontro em grupo foi considerada uma experiência emocionante, pois foi a primeira vez que tiveram a possibilidade de interagir com outras portadoras de HIV. Ficou clara a necessidade de compartilharem seus sentimentos, pois trocaram ideias de uma maneira voraz, falavam 
simultaneamente, riam e choravam. Foi muito importante para Rosa, pois Amor Perfeito, com apenas dezoito anos, havia tido experiência diferente. Conseguiu compartilhar com seus familiares sua problemática, e isso lhe deu uma energia maior.

Atualmente já existe uma política for te e estruturada para a educação continuada dos profissionais da saúde pública. Muitos cursos com patrocínio do governo são realizados, em que os profissionais da rede ambulatorial podem participar e são liberados de seus turnos de trabalho, recebendo apoio financeiro para participação nos eventos. Entretanto, para os profissionais da rede hospitalar, a participação em eventos científicos ou grandes treinamentos ainda fica restrita à disponibilidade econômica dos próprios profissionais. Essa diferença pode estar se refletindo no atendimento, no despreparo dos profissionais dos hospitais, uma vez que a questão econômica faz toda a diferença neste processo.

\section{CONSIDERAÇÕES FINAIS}

A utilização da Teoria de Autocuidado de Dorothea Orem foi fundamental para identificar os inúmeros déficits de autocuidado que as gestantes/puérperas com HIV possuíam. Estes déficits eram decorrentes e tinham agravantes em consequência das condições contextuais em que viviam as gestantes/puérperas por causa do HIV e também pela própria condição referente a idade, capacidade mental, estado emocional, situação econômica e social, e diversidade cultural e social, bem como à aceitação do seu estado soropositivo.

As trocas de experiências que ocorreram tanto nas entrevistas entre enfermeira e gestante ou puérpera quanto no grupo focal, com outras gestantes/puérperas, tornaram oportuna a incorporação de medidas de autocuidado. Isso não só resultou na obtenção de maiores estratégias para engajamento no autocuidado a partir do apoio profissional, mas foi vital para conhecer outras experiências que possibilitaram rever conceitos, condutas e déficits de autocuidado na perspectiva de ampliar os conhecimentos sobre - HIV/AIDS e as representações no cotidiano de cada uma.

A Teoria do Autocuidado possibilitou modificar condutas, traçar estratégias e desenvolver uma ação madura. Desta forma, as pessoas engajadas no autocuidado têm requisitos e são capazes de agenciar seu próprio autocuidado. Foi possível observar que algumas gestantes/puérperas com HIV deste estudo efetivamente realizam ações que refletem seu engajamento no autocuidado: no tratamento, frequentando o serviço de saúde, tomando sua medicação, informando, em alguns casos, os serviços de saúde sobre sua sorologia e necessidade de tratamento.

Finalizando, diríamos que, embora com dificuldades, as gestantes/puérperas com HIV têm conseguido sobreviver ao isolamento e ao preconceito graças ao apoio familiar e da equipe de saúde, em especial das enfermeiras.

\section{Referências}

1. Nascimento D. $O$ final do século XX. In: Nascimento D, organizadora. As pestes do século XX: tuberculose e Aids no Brasil, uma história comparada. Rio de Janeiro(RJ): Fiocruz; 2005. p. 81-111.

2.. Ministério da Saúde (BR) Programa Nacional de DST/AIDS. Dados Epidemiológicos AIDS. [citado 10 jul 2008]. Disponível em http:// www.aids.gov./data/documents/storeddocuments.

3. Nascimento AMG, Barbosa CS, Medrado B. Mulheres de Camaragibe: representação social sobre a vulnerabilidade feminina em tempos de AIDS. Rev Bras Saude Matern Infant 2005 jan/mar; 5(1): 77-86.

4. Ministério da Saúde (BR). Aids: recomendações para prevenção da transmissão vertical do HIV. Brasília (DF); 2004.

5. 10. Ministério da Saúde (BR). Conselho Nacional de Saúde. Resolução $n^{\circ} 196$, de 10 de outubro de 1996. Diretrizes e normas regulamentadoras de pesquisas envolvendo seres humanos. Inf Epidemiol SUS 1996; 5 (2 supl 3): 13-41.

6. Bardin L. Análise de conteúdo. Lisboa (P0): Ed 70; 1979.

7. Foster PC, Janssens NP. Dorotéa Orem. In: George J. Teorias de enfermagem: os fundamentos para a prática profissional. Porto Alegre (RS): Artes Médicas; 1993. p.90-107.

8. Ministério da Saúde (BR). Agência Nacional de Saúde Suplementar. Manual técnico de promoção da saúde e prevenção de riscos e doenças na saúde suplementar. Rio de Janeiro (RJ); 2006.

9. Gonçalves ES. Nutrição superpositiva 2: para gestantes e crianças vivendo com HIV/AIDS. Rio de Janeiro (RJ): ABIA; 1999.

10. Bastos DS, Borenstein MS. Identificando os déficits de autocidado de clientes hipertensos de um centro municipal de saúde. Texto Contexto Enferm 2004 jan/mar; 13 (1): 92-99.

11. Bella ZJD, Martins KF, Veloso I, Bortolini MAT, Sartori MGG, Girão MJBC. Infecção urinária na mulher. [citado 21 jul 2006] Disponível em http://www.uroginecologia.com.br/index/19=nod/11.

12. Alcântara IA. Água - importante e esquecida. Copacabana Runners: corrida e saúde [periódico on-line]. [citado 10 jul 2006]; [1 tela] Disponível em http://www.copacabanarunners.net/agua.html.

13. Cronfli RT. A importância do sono. Cérebro\&Mente: revista eletrônica de divulgação científica em neurociência [periódico on-line]. 2003 abr; [citado 23 jun 2006 ]; [1 tela]. Disponível em: http:// www.cerebromente.org.br/n16/opiniao/dormir-bem1.html.

14. Reis RK, Gir E. Dificuldades enfrentadas pelos portadores sorodiscordantes ao HIV na manutenção do sexo seguro. Rev Latinoam Enfermagem 2005 jan/fev; 13(1): 32-37.

15. Vieira M, Padilha MICS. 0 cotidiano das famílias que convivem com o HIV: um relato de experiência. Esc Anna Nery Rev Enferm 2004 abr; 11(2): 351-357.

16. Tsunechiro MA, Bonadio IC. A família na rede de apoio a gestante. Fam Saude Desenvol 1999 jan/dez; 1(1/2):103-06. 